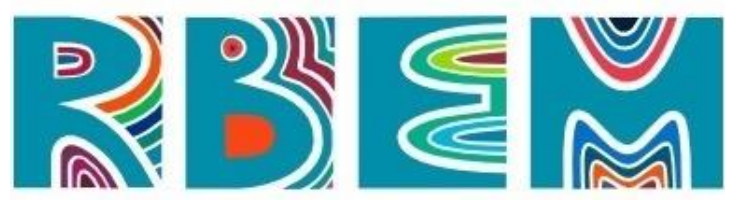

REVISTA BAIANA dE EDUCAÇÃo MATEMÁtICA

\begin{abstract}
$\underline{\text { ARTIGO }}$
do] https://doi.org/10.47207/rbem.v2i01.11984
\end{abstract}

\title{
DRAMATEMÁTICA: TEATRO E MATEMÁTICA
}

\author{
SANT'ANA, Vinícius Borovoy de \\ Secretaria de Estado de Educação de Minas Gerais. Mestre em Ensino. ORCID: 0000-0001-5707-7402. E-mail: \\ viniciusborovoy@gmail.com.
}

PORTO, Maria Beatriz Dias da Silva Maia

Universidade do Estado do Rio de Janeiro. Doutorado em Física. ORCID: 0000-0002-9059-1953. E-mail: beatrizrj@mail.com.

\begin{abstract}
Resumo: O presente trabalho articula o Teatro com a Educação Matemática a partir da elaboração de um curso de extensão intitulado Dramatemática. O curso, com duração de dez encontros, foi realizado na Universidade do Estado do Rio de Janeiro, voltado para professores dos anos iniciais, formados em Matemática, Pedagogia e/ou Curso Normal com atuação docente na Matemática dos anos iniciais. Para o desenvolvimento da pesquisa, foi considerada a pergunta norteadora: Como a articulação do Teatro e da Matemática, a partir dos jogos teatrais e/ou dramáticos pode contribuir para a formação de professores de Matemática atuantes nos anos iniciais? Para responder a esse questionamento, foram aplicadas atividades de linguagem teatral e propostas situações nas quais a Matemática foi apresentada de forma viva e contextualizada. Estabelecemos um grupo colaborativo visando o compartilhamento de saberes e, com a aplicação dos jogos teatrais e/ou dramáticos, conseguimos desenvolver os potenciais crítico, colaborativo e criativo dos participantes envolvidos. A pesquisa realizada teve cunho qualitativo e, para obtenção dos dados, foram realizados a observação participante, registros contínuos, a gravação dos encontros e a avaliação final do curso. Foram elaborados, após a conclusão do curso, dois artefatos educacionais: uma sequência didática, com a coletânea dos planos de aula, e um diário contendo os relatos dos professores que participaram do Dramatemática.
\end{abstract}

Palavras-chave: Teatro. Formação de Professores. Ensino. Matemática

\section{DRAMATEMÁTICA: THEATER AND MATH}

Abstract: The present work articulates Theater with Mathematics Education from the elaboration of an extension course entitled Dramatemática. The course, lasting ten meetings, was held at the State University of Rio de Janeiro, aimed at teachers in the early years, graduated in Mathematics, Pedagogy and/or Normal Course with teaching activities in Mathematics in the early years. For the development of the research, the guiding question was considered: How can the articulation of theater and Mathematics, from theatrical and/or 


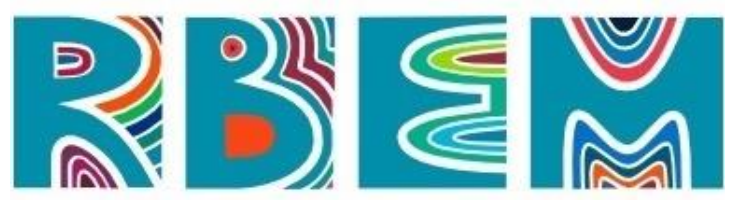

REVISTA BAIANA DE EDUCAÇÃO MATEMÁTICA

dramatic games, contribute to the formation of Mathematics teachers working in the early years? To answer this question, theatrical language activities were applied and situations were proposed in which Mathematics was presented in a lively and contextualized way. We established a collaborative group aimed at sharing knowledge and, with the application of theatrical and/or dramatic games, we were able to develop the critical, collaborative and creative potential of the participants involved. The research carried out had a qualitative nature and, to obtain the data, participant observation, continuous records, recording of meetings and the final evaluation of the course were carried out. After completing the course, two educational artifacts were created: a didactic sequence, with a collection of lesson plans, and a diary containing the reports of teachers who participated in Dramatemática

Keywords: Theater. Teacher training. Teaching. Math

\section{DRAMATEMÁTICA: TEATRO Y MATEMÁTICAS}

Resumen: El presente trabajo articula Teatro con Educación Matemática a partir de la elaboración de un curso de extensión titulado Dramatemática. El curso, de diez reuniones de duración, se llevó a cabo en la Universidad Estatal de Rio de Janeiro, dirigido a docentes en los primeros años, licenciados en Matemáticas, Pedagogía y / o Curso Normal con actividades docentes en Matemáticas en los primeros años. Para el desarrollo de la investigación se consideró la pregunta orientadora: ¿Cómo puede la articulación del teatro y la Matemática, desde los juegos teatrales y / o dramáticos, contribuir a la formación de los profesores de Matemática que trabajan en los primeros años? Para responder a esta pregunta, se aplicaron actividades de lenguaje teatral y se propusieron situaciones en las que las Matemáticas se presentaban de manera viva y contextualizada. Establecimos un grupo colaborativo orientado a compartir conocimientos y, con la aplicación de juegos teatrales y / o dramáticos, logramos desarrollar el potencial crítico, colaborativo y creativo de los participantes involucrados. La investigación realizada tuvo un carácter cualitativo y, para la obtención de los datos, se realizó la observación participante, los registros continuos, la grabación de reuniones y la evaluación final del curso. Una vez finalizado el curso, se crearon dos artefactos educativos: una secuencia didáctica, con una recopilación de planes de lecciones, y un diario que contiene los informes de los profesores que participaron en Dramatemática.

Palavras-Clave: Teatro. Formación de profesores. Enseñando. Matemáticas

\section{Introdução}

A Matemática foi estabelecida e desenvolvida a partir de problemas, geralmente de natureza cotidiana, perpassando por diversas civilizações como: sumérios, egípcios, gregos, chineses, romanos, maias, entre outras. Todas essas civilizações contribuíram para o 


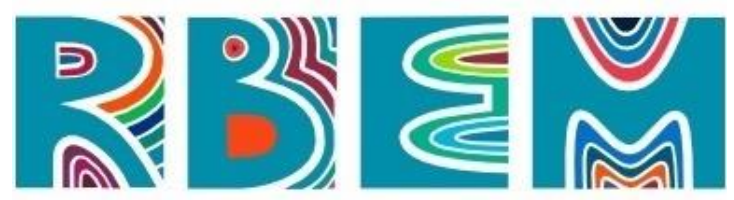

REVISTA BAIANA DE EDUCAÇÃO MATEMÁTICA

desenvolvimento da Matemática, e para conhecimento matemático de hoje, pois, "todo conhecimento é resultado de um longo processo cumulativo de geração, de organização intelectual, de organização social e de difusão naturalmente não-dicotômicos entre si." (D'AMBROSIO, 1996 p. 18).

Entretanto, o que notamos atualmente é que essa Matemática genuinamente cotidiana e investigativa, se reduziu, de uma maneira geral, a uma disciplina formal, universal, descontextualizada e "pronta".

Diante disso, no Brasil, na década de 50, iniciou-se o processo de compreender "quem aprende, como se pode aprender, em quais situações vivem os que aprendem e ensinam, quais recursos estão (ou poderiam estar) à mão, como se relacionam os que ensinam e aprendem Matemática" (Garnica; Souza, 2012, p. 20) com o panorama de Educação Matemática, que culminou, em 1988, no Brasil, com a fundação da Sociedade Brasileira de Educação Matemática (SBEM).

A Educação Matemática, área das Ciências Sociais, dialoga com a Psicologia, Matemática, Antropologia, Sociologia, Filosofia entre outras, pode ser caracterizada como "uma práxis que envolve o domínio do conteúdo específico (a Matemática) e o domínio de ideias e processos pedagógicos relativos à transmissão/assimilação e ou à à $^{\text {ma }}$ apropriação/construção do saber matemático" (FIORENTINI; LORENZATO, 2012, p. 5).

Com a visão da Educação Matemática e da possibilidade de ensino de Matemática mais divertido, experimental, criativo, dialogado, o presente trabalho propõe uma articulação entre o Teatro e a Matemática a partir de um curso de extensão intitulado Dramatemática, onde foi cenário de investigação para a dissertação "Teatro como prática para professores dos anos iniciais atuantes em Matemática" (Sant'ana, 2019) apresentada para o curso Mestrado Profissional de Ensino em Educação Básica.

Para a realização da pesquisa do curso de Mestrado foi proposta a pergunta diretriz: Como a articulação entre o Teatro e a Matemática, a partir dos jogos teatrais e/ou dramáticos podem contribuir para a formação de professores que ensinam Matemática atuantes nos anos iniciais? Em busca de respostas para a pergunta, foi elaborada uma metodologia de ensino de Matemática, na qual o Teatro é capaz de desenvolver competências importantes para o ensino como por exemplo: a memorização, o foco, os desenvolvimentos corporal e espacial, o trabalho em equipe, a escuta, o diálogo e o 


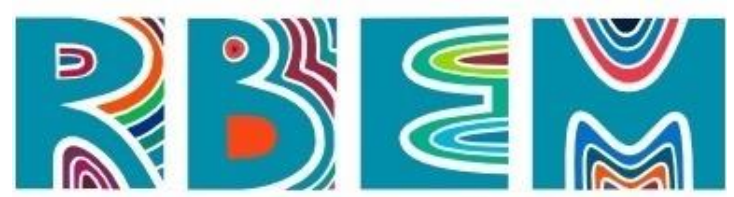

REVISTA BAIANA DE EDUCAÇÃO MATEMÁTICA

respeito, que são importantes tanto para o ensino da Matemática como para as demais disciplinas.

Tendo como fio condutor as atividades contidas no livro de Viola Spolin (2008), realizamos algumas adaptações e, com isso, foi possível durante a realização do curso de extensão mencionado, a abordagem de conteúdos matemáticos como: Diagrama de Venn, figuras geométricas, operações fundamentais, sequência numérica, múltiplos, divisores, paridade, raciocínio lógico, dentre outros. Como a articulação do Teatro e a Matemática é recente, apesar de o lócus da pesquisa serem professores atuantes dos Anos Iniciais, tivemos alguns cursistas que atuavam nos anos finais do Ensino Fundamental e Ensino Médio. Diante dessa realidade, decidimos elaborar e/ou adaptar o máximo de atividades que pudéssemos, não nos limitando ao conteúdo da Matemática apenas para os Anos Iniciais.

As atividades foram elaboradas e adaptadas, de forma que, ao todo, tivemos um total de trinta e duas, entre jogos teatrais e/ou dramáticos, com o objetivo de serem aplicadas junto aos professores participantes. Essa diferenciação de nomenclatura dos jogos é necessária, pois jogos teatrais são realizados necessariamente para uma plateia, enquanto os jogos dramáticos servem como aprimoramento para o ator.

Além da pergunta norteadora, foi importante para o percurso e conclusão da pesquisa o estabelecimento de objetivos. No que diz respeito ao objetivo geral, propusemos: "investigar como os jogos dramáticos e/ou teatrais podem contribuir para a formação continuada dos professores de Matemática dos anos iniciais” e, em relação aos objetivos específicos, elencamos:

- Apresentar aos professores participantes do curso de extensão uma imersão teatral e mostrar a importância de se trabalhar com múltiplas linguagens em sala de aula;

- Estabelecer conexões de conteúdos matemáticos com o cotidiano;

- Propor uma reflexão sobre a importância da matemática, conhecer a sua aplicabilidade e contextualizar a matemática através de jogos dramáticos e/ou teatrais.

Conforme já mencionado, o trabalho aqui apresentado é um recorte do texto da 


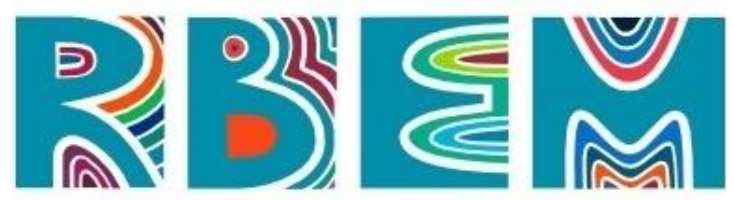

dissertação apresentada para conclusão do curso de Mestrado Profissional que pressupõe, ainda, "necessariamente, apresentar um produto educacional que possa ser disseminado, analisado e utilizado por outros professores." (UNIVERSIDADE DO ESTADO DO RIO DE JANEIRO, 2013, p.12). Dito isso, o curso de extensão Dramatemática, além de ter sido primordial para a obtenção de dados e elaboração do texto da dissertação, proporcionou a elaboração de duas publicações, que se complementam como artefatos educacionais. São eles:

- Curso de Extensão Dramatemática: Sequência Didática (SANT’ANA; PORTO, 2019a)

- Curso de Extensão Dramatemática: Diário, aplicações e experiência aula a aula (SANT'ANA; PORTO, 2019b)
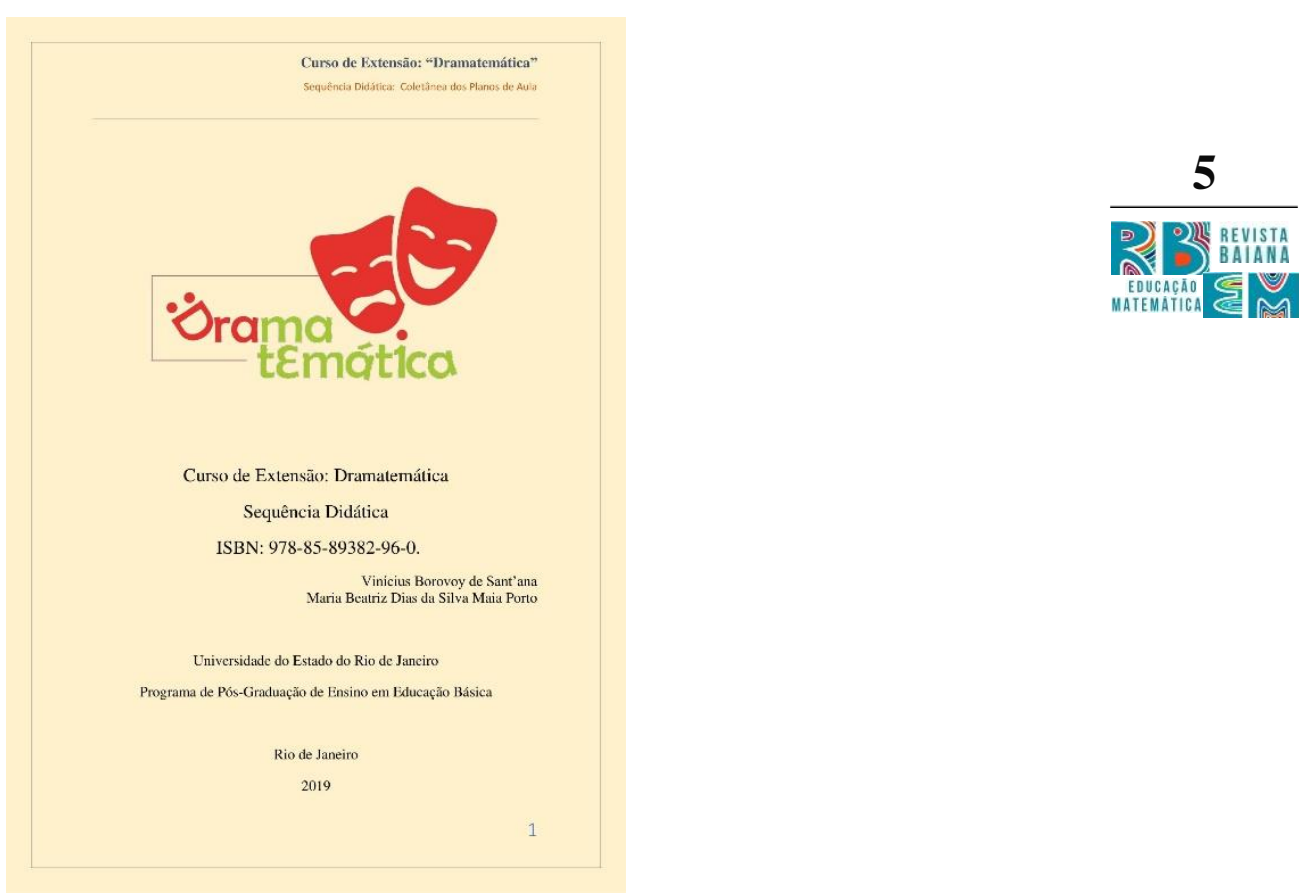

Figura 1: Curso de Extensão: Dramatemática, Sequência Didática - Coletânea dos Planos de Aula (Sant'ana e Porto, 2019a, p. 1) 

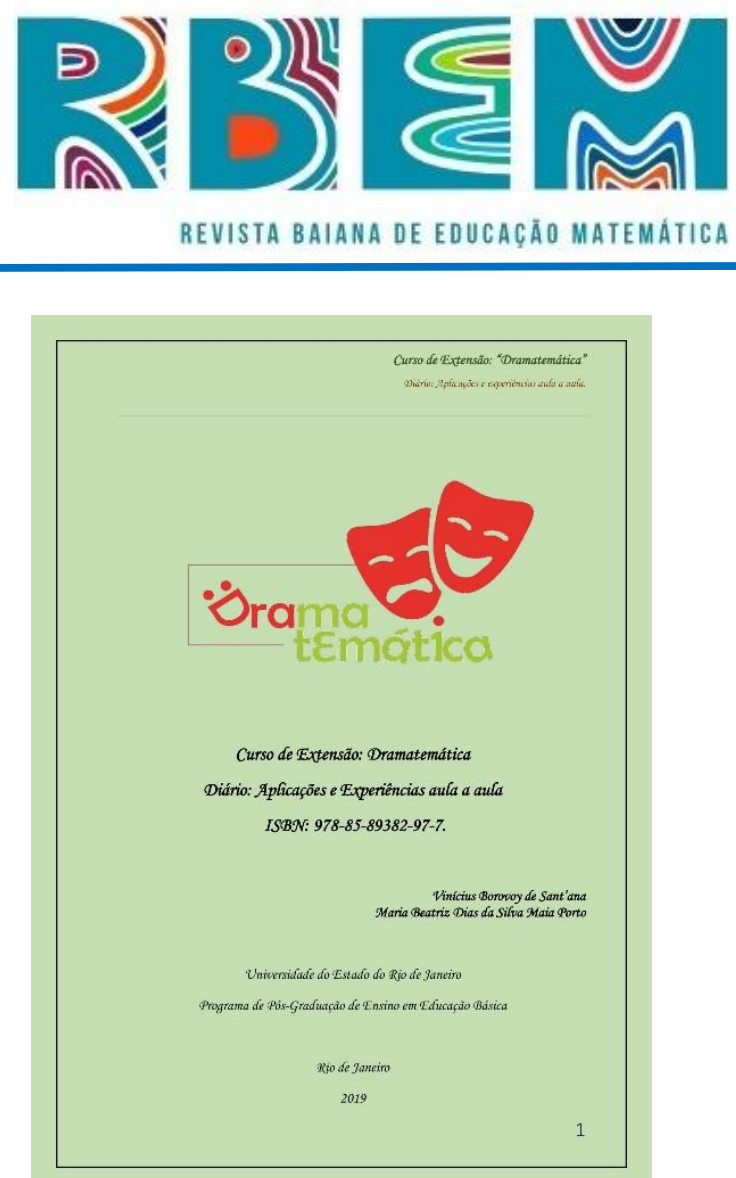

Figura 2: Curso de Extensão: Dramatemática , Diário: Aplicações e Experiências Aula a Aula (Sant'ana e Porto, 2019b, p. 1)

O primeiro dos $\operatorname{artefatos}^{1}$, cujas capas estão ilustradas acima, que constituem o produto, traz os planos de aula que compreenderam o Dramatemática, já o segundo ${ }^{2}$,

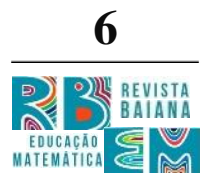
contempla o processo do curso, com os relatos das atividades aplicadas, as aplicabilidades e alguns dos registros fotográficos realizados durante o processo.

$\mathrm{Na}$ seção a seguir, descreveremos parte do curso Dramatemática assim como algumas atividades aplicadas durante a sua realização e sua fundamentação teórica.

\section{Dramatemática: elaboração, atividades e fundamentação teórica}

A articulação do Teatro com a Matemática surgiu em 2015 com o Dramatemática em formato de oficina (Sant'ana, 2015). Naquele momento, a oficina Dramatemática tinha duração aproximada de quatro horas e era aplicada em colégios e congressos, o que gerou dados de pesquisa para a realização de alguns trabalhos.

\footnotetext{
${ }^{1}$ Maiores informações: https://educapes.capes.gov.br/handle/capes/564444

${ }_{2}^{2}$ Maiores informações: https://educapes.capes.gov.br/handle/capes/564445
} 


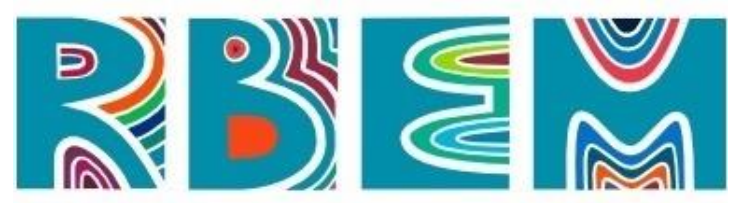

REVISTA BAIANA DE EDUCAÇÃO MATEMÁTICA

Em 2017 a oficina Dramtemática foi ampliada e tornou-se um curso de extensão, pois este seria objeto de investigação de pesquisa a ser realizada no curso de Mestrado. Dessa forma, a estruturação e o planejamento do curso, compreenderam dez encontros, com duração de três horas cada, realizados semanalmente.

Uma vez elaborado, em maio de 2018, a divulgação do Dramatemática foi realizada através de e-mails, de WhatsApp e da rede social Facebook. Para a divulgação, foi elaborado um cartaz (Figura 3), contendo o site www.dramatematica.com , onde a inscrição era feita através de um formulário.

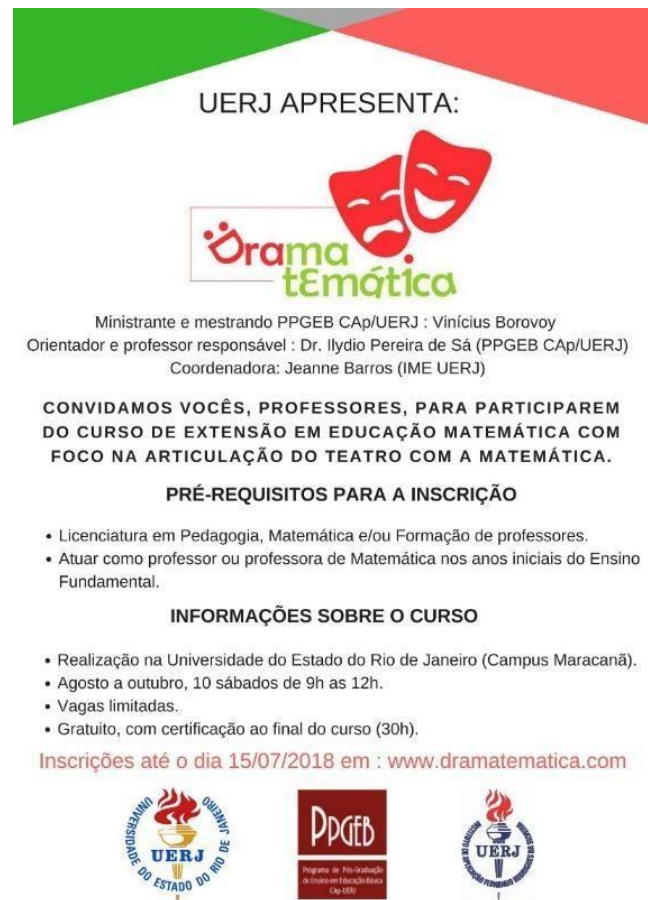

Figura 3: Folder de divulgação do curso Dramatemática (Sant'ana, 2019)

Para a realização da inscrição, o candidato precisaria ter formação completa em Matemática, Pedagogia e/ou Curso Normal. Além disso, deveria estar em atuação como professor regente de turma na disciplina de Matemática nos anos iniciais do Ensino Fundamental.

Foram muitos inscritos e como critérios para seleção adotamos: ordem de inscrição, 


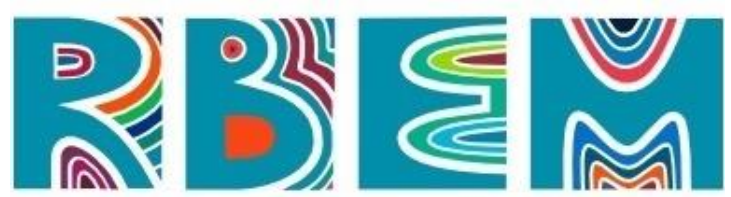

REVISTA BAIANA DE EDUCAÇÃO MATEMÁTICA

preenchimento completo do formulário, disponibilidade para comparecer aos encontros e liberação de utilização de imagem e áudio. Foram selecionados vinte e cinco candidatos. Destes, quinze iniciaram o processo e doze concluíram. Voltamos a afirmar aqui que tivemos cursistas que atuavam nos Anos Finais do Ensino Fundamental.

No que diz respeito aos encontros, todos possuíam como estrutura básica: conversa inicial, alongamento corporal e vocal, realização de jogos dramáticos e/ou teatrais e conversa final.

Para a obtenção dos dados, os encontros tinham gravação em áudio, registros fotográficos e, ao final, eram escolhidos dois participantes para os quais era entregue um caderno, para que relatassem sobre a aula em questão. A cada aula esse procedimento era repetido, sempre trocando os participantes escolhidos.

Cabe ressaltar que em todo o processo de pesquisa, não nos preocupamos com dados numéricos e sim com a apresentação de novas metodologias de ensino para a Matemática. Portanto, trata-se de uma pesquisa de cunho qualitativo pois "tem como foco entender e interpretar dados e discursos, mesmo quando envolve grupos de participantes" (D’AMBROSIO, 2013, p. 12) e além disso, "lida e dá atenção às pessoas e às suas ideias, procura fazer sentido de discursos e narrativas que estariam silenciosas". (IBID, p. 21).

Para o desenvolvimento da pesquisa foi realizada a técnica de observação participante. O pesquisador esteve presente em todos os encontros, na aplicação das atividades e nas reuniões após cada aula, onde eram fornecidos os feedbacks dos cursistas, acompanhou o grupo presencialmente por mais de 3 meses, e também virtualmente, uma vez que as trocas continuaram, pelo menos, até a defesa da Dissertação. Segundo May a observação participante é:

O processo no qual um investigador estabelece um relacionamento multilateral e de prazo relativamente longo com uma associação humana na sua situação natural com o propósito de desenvolver um entendimento científico daquele grupo (2001: 177).

Para o trabalho em questão, apresentaremos as atividades que mais foram comentadas pelos professores participantes, nos cadernos que entregávamos aula a aula, e no questionário final sobre o curso.

Cabe mencionar que nem todas as atividades aplicadas durante a realização do curso 


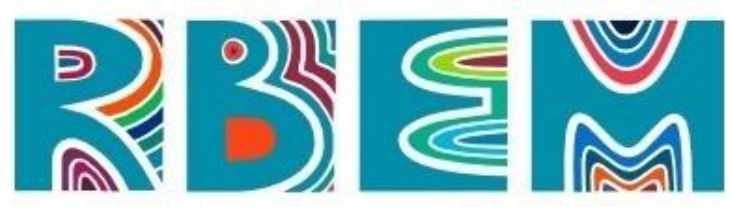

REVISTA BAIANA DE EDUCAÇÃO MATEMÁTICA

têm um nome específico. O processo de "caminhar pelo espaço", por exemplo, é um recurso muito utilizado para o desenvolvimento do ator. Cada atividade "caminhar" seguia uma numeração em sequência. Dessa forma tivemos: caminhar pelo espaço 1, caminhar pelo espaço 2, e assim por diante.

O quadro a seguir descreve algumas das atividades propostas e apresenta os objetivos de cada uma delas.

Quadro 1: Atividades do curso de extensão Dramatemática

\begin{tabular}{l} 
Atividade: Dança das Figuras Geométricas \\
\hline Descrição: Para esta atividade, o mediador deve "desenhar" algumas figuras \\
geométricas no chão do espaço disponível. Recomendamos que para isso seja utilizada \\
fita adesiva branca. A atividade inicia com os participantes caminhando pelo espaço e, \\
ao comando do mediador, através de palmas, eles devem se direcionar para "dentro" de \\
uma das figuras desenhadas. A seguir, os participantes que estiverem "dentro" dessa \\
figura devem falar características dela. Por exemplo, quantidade de lados, de ângulos, \\
soma dos ângulos internos, etc. \\
Obs: Para a nossa aula, "desenhamos" um quadrado, um retângulo, um círculo e um \\
triângulo. Não estipulamos o máximo de participantes em cada figura, mas informamos \\
que nenhuma delas poderia ficar vazia.
\end{tabular}

Objetivos: Reconhecimento das figuras geométricas e suas características, trabalho em grupo.

Atividade: Que horas são?

Descrição: Baseado em Spolin (2005, p. 96), esse jogo teatral explora a medida do tempo (horas e minutos). Cada aluno recebe um horário da professora e a turma deve descobrir que horas são por meio das ações realizadas por meio de mímica, sem sons. Poderia mostrar o aluno, por exemplo, chegando ou saindo de determinado lugar; indo dormir, almoçar, estudar.

Obs: Nesta aula, separamos os participantes em quatro grupos, tendo em mente quatro horários diferentes. Escolhemos 6 horas da manhã, 6 horas da noite (18h), 12 horas da manhã (meio dia) e 12 horas da noite (meia noite). A proposta era abordar esses números 6 e 12 , em diferentes situações. 


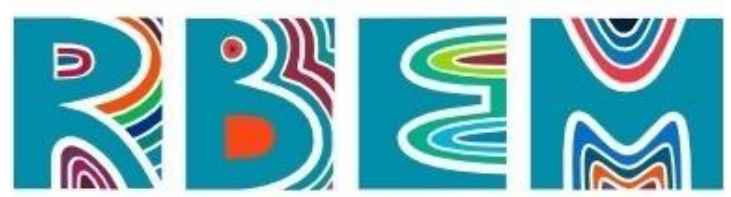

REVISTA BAIANA DE EDUCAÇÃO MATEMÁTICA

Objetivos: Desenvolver a imaginação, a contextualização, introduzir conceitos como horas e minutos.

\begin{abstract}
Atividade: Caminhar pelo espaço 8
Descrição: O mediador precisa desenhar, antes do início da atividade, dois ou mais conjuntos formando um diagrama de Venn. O mediador estipula características em cada conjunto. Por exemplo: conjunto dos homens, conjunto das pessoas maiores de $1,70 \mathrm{~cm}$. E assim, inicia-se a atividade com os participantes caminhando pelo espaço. Ao comando do mediador, com palmas, os estudantes devem se direcionar para o diagrama que condiz com as suas características. Caso ele tenha duas ou mais características, deve procurar as devidas interseções.
\end{abstract}

Objetivos: Desenvolvimento espacial, representação de conjunto, união e interseção.

\title{
Atividade: Contar até 10
}

Descrição: Um aluno inicia a sequência e cada aluno da roda, não necessariamente na ordem que estão posicionados, acrescenta um número. Se dois ou mais alunos falarem juntos, começa tudo de novo. Só com o olhar sobre a roda, cada aluno deve perceber se pode falar ou não. O aluno deve ter prontidão para não deixar "buraco" por muito tempo, pois a rapidez de resposta está sendo trabalhada.

Objetivos: Desenvolver a atenção, a concentração, a visão periférica e a participação em grupo.

\section{Atividade: Jogo do Plim}

Descrição: $\mathrm{O}$ grupo se dispõe em círculo. $\mathrm{O}$ mediador escolhe um número dentre $2 \mathrm{e}$ 10 e comunica aos participantes. Toda vez que aparecer um múltiplo desse número escolhido, o participante da vez deve dizer PLIM. Por exemplo, caso o mediador escolha o número três. A sequência numérica seria: um, dois, PLIM, quatro, cinco, PLIM. Podemos ampliar para "PLIM", "PLAM" "PLUM. O conceito é o mesmo, porém devem-se escolher 3 números. Os múltiplos de um número seriam falados "PLIM", do outro "PLAM" e do último "PLUM". Por exemplo, se forem escolhidos os números 3, 4, 5, a sequência ficaria: um, dois, PLIM, PLAM, PLUM, PLIM, sete, PLAM, PLIM, PLUM. 


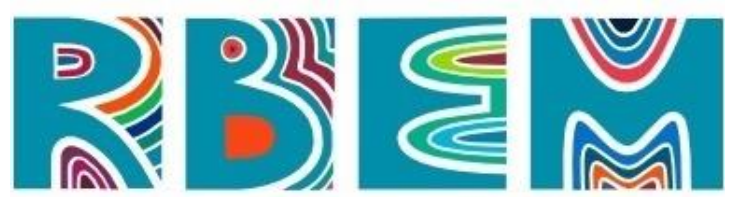

REVISTA BAIANA DE EDUCAÇĀO MATEMÁTICA

Objetivos: Trabalhar múltiplos dos números, percepção uns dos outros e agilidade no raciocínio.

\section{Atividade: Hipnotismo}

Descrição: Um participante irá pôr a mão a poucos centímetros do rosto da sua dupla e este ficará hipnotizado, devendo manter o rosto à mesma direção da mão do hipnotizador. Este inicia uma série de movimentos com a mão, fazendo com que o seu companheiro faça com o corpo todas as contorções possíveis mantendo a distância. Após o comando do mediador troca-se de posições.

Objetivos: Desenvolver a percepção espacial, foco, confiança e trabalho em grupo.

Fonte: Santa'ana e Porto, 2019a

As seis atividades anteriores, assim como as outras vinte e seis, tiveram como objetivo, proporcionar uma Matemática mais dialógica, participativa, divertida, criativa e colaborativa. Entendemos que esse trabalho traz um pioneirismo, visto que a articulação do Teatro com a Matemática é algo ainda pouco explorado. Em março de 2018, quando foi realizada uma revisão bibliográfica no portal da Coordenação de Aperfeiçoamento de Pessoal de Nível Superior (CAPES) e no porto da Biblioteca digital de Teses e Dissertações (BDTD), ainda não havia, no Brasil, um trabalho que articulasse os jogos teatrais e/ou dramáticos, em formato de um curso de extensão e aplicados para professores. (SANT’ANA, 2019)

O Teatro e a Matemática, na maioria das vezes, são retratados com encenações, onde se abordam conteúdos, ou com encenações de livros como "o Homem que calculava", “o diabo dos números" entre outros. O que propomos, a aplicação com jogos teatrais e/ou dramáticos é um campo ainda com poucas referências. Os trabalhos de Alvarito Mendes Filho (2016), Hannah Dora de Garcia e Lacerda (2015) trazem alguns jogos teatrais aplicados com estudantes da Educação Básica. Já o trabalho da Thaís Philipsen Grützmann (2009) articula o Teatro e a Matemática com licenciandos.

Dessa forma, o dramatemática, diferente dos referenciais da época, abordou, em 


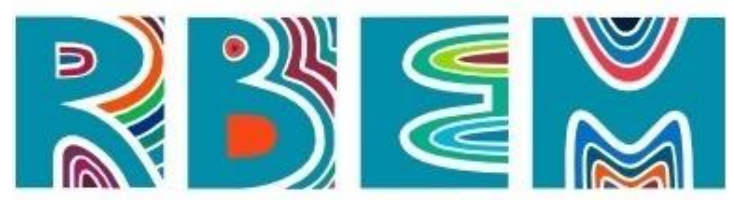

REVISTA BAIANA DE EDUCAÇÃO MATEMÁTICA

uma perspectiva de formação continuada, atividades envolvendo Teatro e Matemática. Essas atividades, mesmo não seguindo um ano de escolaridade específico, abordam alguns conteúdos matemáticos de uma forma não convencional. Ao final das aulas, eram discutidas atividade por atividade, momento em que o pesquisador apresentava os conteúdos que poderiam ser abordados e os participantes concordavam ou não, e davam suas sugestões, em uma perspectiva de grupo colaborativo.

O Dramatemática foi desenvolvido tendo como base os pressupostos teóricos, principalmente, de Spolin (2008), D’Ambrosio (1996) e Skovsmose (2013).

Como os jogos teatrais e/ou dramáticos se constituem como a principal prática da pesquisa, os conceitos de Viola Spolin são utilizados:

O jogo é democrático! Todos podem aprender jogando! O jogo estimula vitalidade, despertando a pessoa como um todo - mente e corpo, inteligência e criatividade, espontaneidade e intuição - quando todos, professor e alunos unidos estão atentos para o momento presente. (2008, p. 30)

A relação do Teatro com a Matemática, por serem atividades práticas e acompanhadas pelo professor, estabelece um posicionamento mais ativo, tornando o aluno protagonista do seu processo de ensino e aprendizagem, que é um pressuposto de D’Ambrosio (1996).

D'Ambrosio (2011) também contribui para este trabalho com o conceito de Etnomatemática, que constitui-se como:

[...] a matemática praticada por grupos culturais, tais como comunidades urbanas e rurais, grupos de trabalhadores, classes profissionais, crianças de uma certa faixa etária, sociedades indígenas e tantos outros grupos que se identificam por objetivos e tradições comuns aos grupos. (D’AMBROSIO, 2011, p. 9).

A articulação da Matemática com o Teatro no curso de extensão Dramatemática, constitui uma prática de "Etnomatemática", pois formamos um grupo com um propósito em comum: ensinar a Matemática de forma mais divertida. Além disso, com a realização de cenas em que a Matemática está presente no dia a dia, também estamos realizando Etnomatemática pois, “a utilização do cotidiano das compras para ensinar matemática revela práticas apreendidas fora do ambiente escolar, uma verdadeira etnomatemática do comércio." (D“eAMBROSIO, 2011, p. 23). 


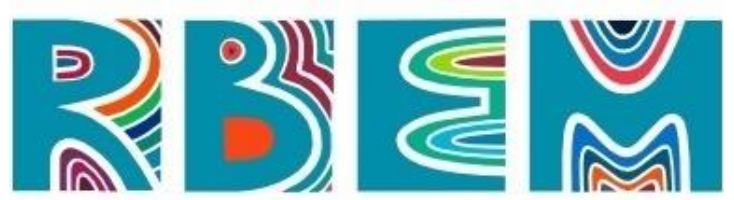

REVISTA BAIANA DE EDUCAÇÃO MATEMÁTICA

A abordagem da Matemática através do Teatro pode romper barreiras do ensino tradicional e expositivo, e pode ser considerada também como uma prática de insubordinação criativa, uma vez que há um ruptura de modelos preestabelecidos. Segundo Beatriz D’Ambrosio e Celi Lopes (2015, p.4), é importante que o profissional da educação

busque formar estudantes éticos e solidários não deve conceber o ensino como transmissão de conceitos já elaborados e construídos, não deve limitar sua prática docente apenas aos objetivos previamente determinados, sem considerar o contexto no qual seu aluno está inserido.

Por fim, Ole Skovsmose (2013) traz o conceito de Educação Matemática Crítica e os cenários para investigação. As atividades selecionadas para esse trabalho foram jogos dramáticos, porém, ao longo do curso, propusemos alguns jogos teatrais que tinham o objetivo de teatralizar algumas situações onde a matemática está presente. Desta forma, o curso de extensão foi o palco para essas investigações e pode se caracterizar como uma prática de Educação Matemática Crítica, por trazer a importância da Matemática como formação de pessoas conscientes com os seus direitos e deveres.

\section{Aplicabilidade do Curso}

Em relação às cinco atividades supracitadas, será apontado aqui a forma de sua utilização pelos cursistas e o feedback que nos foi dado em relação a elas. Cabe ressaltar que os doze professores que concluíram o curso não serão identificados por nome. Utilizaremos a notação P1 até P12, seguindo a ordem alfabética dos seus nomes.

No que diz respeito ao jogo dramático "dança das figuras geométricas", a participante P3 relatou que "fazia parte do conteúdo programático do $1^{\circ}$ ano de escolaridade e que os alunos adoraram. Foi uma forma lúdica e fácil de entender o tema". O participante P6 aplicou em suas turmas de $8^{\circ}$ ano e "eles absorveram as propriedades dos polígonos com maior facilidade e, na hora das avaliações, se saíram melhor do que os alunos dos anos anteriores".

Em relação à atividade "Que horas são?”, a participante P5 relatou que "essa atividade já faz parte da minha memória afetiva pela receptividade, fascínio e aprendizagem do conteúdo pelos alunos". 


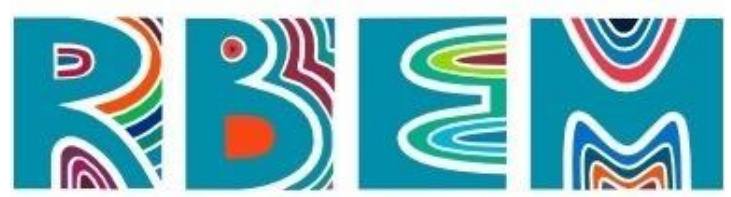

REVISTA BAIANA DE EDUCAÇÃO MATEMÁTICA

Para o "Caminhar pelo espaço 8", o participante P2 utilizou "a atividade feita com barbantes e fita adesiva" para ensinar operações com conjuntos para a turma de $1^{\circ}$ ano do ensino médio. Já a participante P10 a adaptou e, ao invés de explorar as características físicas como fizemos no curso, ela utilizou múltiplos e divisores de números naturais.

A atividade "Contar até 10" foi aplicada por três participantes. A participante P7 considerou interessante pois "eles perceberam a importância de esperar o colega falar". Outro ponto que a participante destacou foi que "um aluno que organizou a turma para que todos conseguissem participar”. Já a participante P9, adaptou a atividade e ao invés de uma contagem de forma aleatória, ela pediu para que seus alunos contassem até dez, seguindo a ordem da roda. Porém, para dinamizar, ela alterava o ritmo da contagem com o bater de palmas.

Por fim, o participante P12 relatou que, "os alunos estavam ansiosos para não falar juntos". Após a atividade, ele promoveu uma conversa e os alunos "relataram dificuldade em manter a sequência numérica, e outros conseguiram perceber que devemos prestar atenção ao outro e ouvir o colega quando ele fala". Ele finaliza dizendo que "o bom dessa dinâmica foi o entendimento do respeitar o espaço de fala do outro, o que foi muito significativo para mim como docente".

A próxima atividade selecionada é o "Jogo do plim", aplicado pela participante P11. Ela aplicou nas suas turmas de $6^{\circ}$ e $7^{\circ}$ anos e, segundo a professora, "eles adoraram e pediram para repetir".

A última atividade selecionada foi o "Hipnotismo", uma atividade também com um retorno bastante positivo, pois segundo os participantes, ela trabalha concentração, confiança, respeito ao outro, respeito ao espaço em conjunto que são competências importantes.

As seis atividades selecionadas são consideradas jogos dramáticos. Como o curso terminou em novembro de 2018, acreditamos que os professores participantes não tenham tido tempo hábil para desenvolver algum jogo teatral. Isso se deve porque para aplicar um jogo teatral, é preciso de algumas aulas prévias com a aplicação de jogos dramáticos para ambientar esse uso com teatro. 


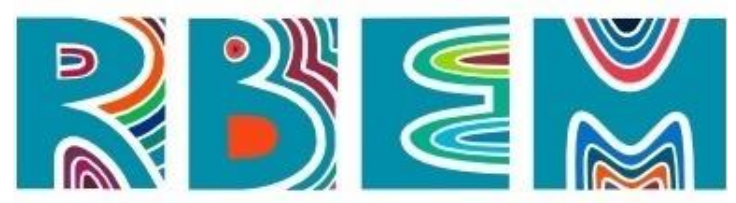

\section{Resultados e Discussões}

Após a realização do curso, era importante uma avaliação para entender se a experiência tinha sido positiva para os participantes. Aula a aula, entregávamos dois cadernos para diferentes participantes que relatavam sobre a respectiva aula e, além do caderno, algumas questões foram elaboradas, e por eles respondidas, para auxiliar a coleta de dados. As questões foram:

1. Relate um pouco sobre a sua formação acadêmica e a sua experiência profissional;

2. Cite três pontos positivos do curso e três pontos que possam ser melhorados;

3. Comente um pouco sobre a realização do curso, se teve utilidade para a sua prática docente;

4. Em relação às atividades aplicadas ao longo do curso, você utilizou alguma delas? Se sim, comente a respeito. Aponte a atividade realizada, a série em que foi aplicada e relate como foi o retorno dos alunos.

5. Quais foram as principais contribuições do curso para a sua vida profissional e pessoal?

6. Essa pergunta é livre, escrevam aqui suas opiniões, sugestões e críticas para o andamento do curso "Dramatemática".

Para realizar a análise das respostas, elaboramos categorias, através do pensamento de Bardin acerca da categorização:

classificação de elementos constitutivos de um conjunto, por diferenciação e, seguidamente, por reagrupamento segundo o gênero (analogia), com os critérios previamente definidos. As categorias, são rubricas ou classes, as quais reúnem um grupo de elementos ... sob um título genérico, agrupamento esse efetuado em razão dos caracteres comuns destes elementos. (2006, p. 117).

Com base nesses pressupostos, as respostas dos participantes foram concentradas nas seguintes três categorias:

- Contribuição para Formação Continuada a partir das atividades, troca de saberes, experiências e interações do grupo;

- Aplicabilidade e a contextualização a partir dos jogos dramáticos e/ou teatrais;

- Desmistificação da matemática (A matemática não é um Monstro). 


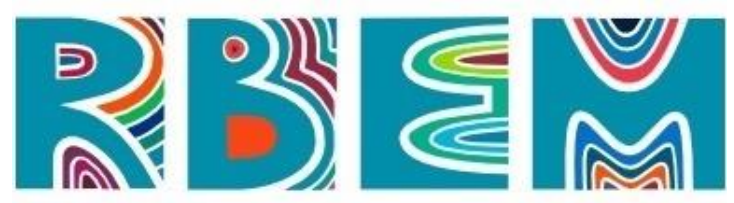

REVISTA BAIANA DE EDUCAÇÃO MATEMÁTICA

Dentre as respostas fornecidas foram selecionados, para a primeira categoria dezenove trechos, treze trechos para a segunda e para a última categoria, foram destacados sete trechos. Para exemplificar a análise realizada, elaboramos o quadro a seguir com dois trechos para cada categoria. Além disso, no quadro está destacado o participante e em qual pergunta ou questão esse trecho estava presente.

Quadro 2: Alguns trechos das respostas dos participantes

\begin{tabular}{|c|c|}
\hline $\begin{array}{l}\text { Contribuição para Formaç } \\
\text { experiências e interações d }\end{array}$ & vidades, troca de saberes, \\
\hline Participante & Pergunta \\
\hline $\mathrm{P} 2$ & 5 \\
\hline $\begin{array}{l}\text { "Me ajudou a entender melh } \\
\text { para assim poder agregar em }\end{array}$ & os e buscar ferramentas \\
\hline P5 & 3 \\
\hline
\end{tabular}

\section{Aplicabilidade e a contextualização a partir dos jogos dramáticos e/ou teatrais}

\begin{tabular}{l|l} 
P8 & 2 \\
\hline
\end{tabular}

"Foi de muita utilidade. O diferencial foi a possibilidade de vivenciar as atividades. Sentir-se como a clientela na qual a atividade será aplicada melhora a capacidade de avaliar."

\begin{tabular}{|l|c|}
\hline P10 & 2 \\
\hline “O curso trouxe uma contribuição significativa para a prática docente em sala de aula, \\
despertou a conexão matemática com diversas atividades."
\end{tabular}

\section{Desmistificação da matemática (A Matemática não é um Monstro)}

\begin{tabular}{l|r} 
P1 & 2 \\
\hline
\end{tabular}

"Tirou a ideia de que a matemática não é a vilã, que pode ser trabalhada de forma lúdica e interativa, despertando nos alunos o interesse por vários assuntos."

\begin{tabular}{l|l} 
P12 & 3
\end{tabular}

"Como uma participante disse em uma das aulas, matemática sempre foi um monstro para mim. E escolho sempre fazer atividades que envolvam essa disciplina, o curso me deu um leque maior de possibilidades para quebrar meus próprios paradigmas e desenvolver uma aula mais dinâmica."

Fonte: Sant'anna, 2019 


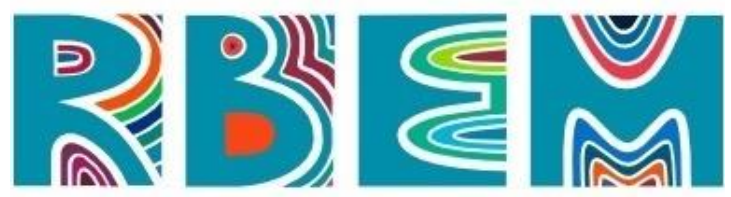

REVISTA BAIANA DE EDUCAÇÃO MATEMÁTICA

A partir dos relatos acima, o Teatro com o seu potencial inter/transdisciplinar pode ser:

[...] um forte instrumento articulador da diversidade da escola, capaz de proporcionar, de alguma forma, o início de uma aproximação do aluno com a complexidade social em que vivemos, colocando estudantes e professores das diversas disciplinas bem mais próximos dos objetivos elencados nas Diretrizes Curriculares Nacionais Gerais da Educação Básica (MENDES FILHO, 2016, p. 32)

O Teatro pode, então, ser um instrumento não só para a Matemática, mas para diversas disciplinas, seja para uma introdução de conteúdo, através de jogos teatrais ou de encenações, até mesmo como finalização de um conteúdo, de um tema, de um bimestre escolar.

\section{Considerações Finais}

Mediante os relatos dos participantes nos formulários de avaliação e nos cadernos que entregávamos aula a aula, entendemos que respondemos à pergunta norteadora "qual matemática os professores dos Anos Iniciais desenvolvem a partir de jogos dramáticos e/ou teatrais?".

Os jogos teatrais e/ou dramáticos como metodologia de ensino para a matemática são capazes de proporcionar um ensino mais divertido, criativo, colaborativo, investigativo e significativo.

Apesar de termos estabelecido o público alvo, professores atuantes da Matemática dos Anos Iniciais, alguns professores eram pedagogos e outros formados em Matemática atuntes nos Anos Finais do Ensino Fundamental, o que ampliou a discussão, não se limitando a conteúdos dos anos iniciais. Além disso, o objetivo do curso, era proporcionar o máximo de atividades com a articulação do Teatro e a Matemática. Como é algo ainda pouco explorado, ainda não é possível elaborar atividades seguindo um determinado ano escolar e sim, tentamos apresentar atividades que podem ser adaptadas e apresentadas desde o primiero segmento do Ensino Fundamental até o Ensino Médio.

Além dos relatos, que apontam que o curso foi importante enquanto formação docente e quebra de paradigmas, percebemos que o curso teve aplicabilidade e replicabilidade, pois várias atividades foram realizadas e/ou adaptadas pelos participantes 


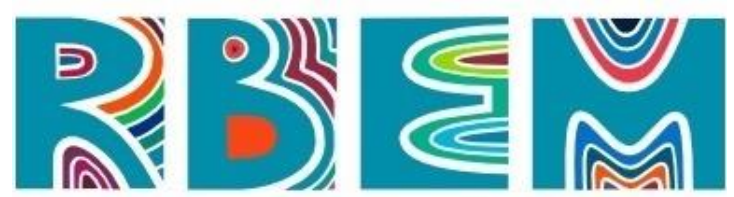

REVISTA BAIANA DE EDUCAÇÃO MATEMÁTICA

em suas respectivas turmas.

Em relação aos produtos educativos, a coletânea de atividades aula a aula pode auxiliar o professor que queira utilizar algumas atividades diferenciadas, pois o produto tem a descrição de cada jogo, assim como os objetivos. Em relação ao Diário, ele proporciona ao leitor, mais detalhes sobre as trocas e experiências ao longo do curso. É recomendável que os dois volumes sejam utilizados em conjunto.

Por fim, esperamos que o trabalho desenvolvido possa ajudar professores a diferenciarem suas salas de aula e que surjam mais Dramatemáticas.

\section{Referências}

BARDIN, L. Análise de conteúdo. Lisboa: Edições 70, 2006. (Obra original publicada em 1977)

D'AMBROSIO, U. Prefacio. In: BORBA, Marcelo De Carvalho. Pesquisa Qualitativa em Educação Matemática. Belo Horizonte: Autêntica Editora, 2013.

D'AMBROSIO, U. Educação Matemática: da teoria à prática. Campinas: Papirus, 1996. . Etnomatemática: elo entre as tradições e a modernidade. Belo Horizonte:

Autêntica Editora, 2011.

D’AMBROSIO, B.S; LOPES, C.E. Insubordinação Criativa: um convite à reinvenção do educador matemático. Bolema, Rio Claro,SP, v. 29, n. 51, p. 1-17, abr. 2015.

Disponível em: http://www.scielo.br/pdf/bolema/v29n51/1980-4415-bolema-29-510001.pdf Acesso em: 17 nov 2020.

FIORENTINI, D.; LORENZATO, S. Investigação em educação matemática: percursos teóricos e metodológicos. Campinas, SP: Autores Associados, 2012.

GARNICA, A. V. M.; SOUZA, L. A. de. Elementos da História da Educação Matemática. São Paulo: Cultura Acadêmica, 2002.

GRÜTZMANN, T.P. A formação dos professores de matemática por meio dos jogos teatrais. Dissertação (Mestrado) - Faculdade de Física, Pós-Graduação em Educação em Ciência e Matemática, PUCRS. Porto Alegre, 2009.

LACERDA, H.D.G. Educação Matemática encena. 179f. Dissertação (Mestrado) Universidade Estadual Paulista, Instituto de Geociências e Ciências Exatas, Rio Claro, 2015. 


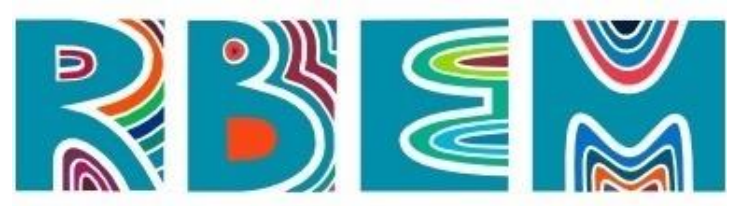

REVISTA BAIANA DE EDUCAÇÃO MATEMÁTICA

MAY, T. Pesquisa social. Questões, métodos e processos. Porto Alegre, RS, Artmed, 2001.

MENDES FILHO, A. Matemática em cena: aprendizagens por meio da montagem e encenações de peças do Teatro Matemático. 191f. Dissertação (Mestrado) - Instituto Federal do Espírito Santo, Programa de Pós-Graduação em Educação em Ciências e Matemática, Vitória, 2016.

SANT'ANA, V.B. de. Teatro como prática para professores dos anos iniciais atuantes em Matemática. Orientadora: Maria Beatriz Dias da Silva Maia Porto. Dissertação (Mestrado) Universidade do Estado do Rio de Janeiro, Instituto de Aplicação Fernando Rodrigues da Silveira.2019. 113 f.: il. Disponível em: https://drive.google.com/file/d/1_JTV1BN3qrpE46_WsiP4IHv-NPwNcGem/view

SANT'ANA, V.B. de; PORTO, M.B.D.S.M. Curso de Extensão: Dramatemática Sequência Didática, 2019a. Disponível em: http://educapes.capes.gov.br/handle/capes/564444 Acesso em 17 set 2020.

SANT'ANA, V.B. de; PORTO, M.B.D.S.M. Curso de Extensão Dramatemática, Diário: Aplicações e experiências aula a aula, 2019b. Disponível em: http://educapes.capes.gov.br/handle/capes/564445. Acesso em 17 set 2020.

SKOVSMOSE, O. Educação Matemática Crítica: a questão da democracia. São Paulo: Papirus, 2013.

SANTANA, V.B. de. Dramatemática. In: VIII Scientiarum História. Rio de Janeiro: UFRJ, 2015. Disponivel em :

http://www.hcte.ufrj.br/downloads/sh/sh8/SH/trabalhos\%20posteres\%20completos/DRAMA TEMATICA.pdf. Acesso em 05 ago 2021.

SPOLIN, V. Jogos teatrais para a sala de aula: um manual para o professor. São Paulo: Perspectiva, 2008.

UNIVERSIDADE DO ESTADO DO RIO DE JANEIRO. Deliberação $N^{o}$ 28/2013 Disponível em:http://www.boluerj.uerj.br/pdf/de_00282013_22082013.pdf. Acesso em: Acesso em 17 set 2020.

Artigo submetido em: 12/06/2021

Artigo aceito em: 07/08/2021 